\title{
Tourism Industry Chain Analysis Based on Informatization Perspective
}

\author{
Jie Yue \\ School of Management, Jiaozuo Teachers College, Jiaozuo, 454000, China
}

\author{
Keywords: Informatization, Tourism, Industry chain
}

\begin{abstract}
Informatization age had a profound impact on the tourism industry chain, not only to better enhance the contact degree of tourism industry chain, promote China's tourism industry chain to have continuously extension, but also speed up the effective transformation of China tourism industry chain, create a healthy and positive image of China's tourism industry chain. This paper describes the basic characteristics of the current information technology in China, discusses the major impact of information technology on our tourism industry chain, and proposes the strategies for strengthening tourism industry chain in the information age.
\end{abstract}

\section{Introduction}

In the current rapid development of information technology, we should actively promote the use of information technology in the tourism industry chain; through the information technology, making continuous improvement for the informatization level possessed by the tourism industry. In the information age, all kinds of businesses have new changes, more positive and rational response to new changes can be said to be the inevitable choice of China's tourism industry chain development. To this end, to make a research for the current tourism industry, in-depth analysis of the countermeasures to strengthen the tourism industry chain under informationation perspective, which is to ensure that our tourism industry can obtain important guarantee of sustainable development in the new situation.

\section{The basic characteristics of China's current informatization}

First, the sharing of information. With the development of information technology, the traditional Internet technology gradually upgrading. For example, in the past the network cable is always join the network core components, only the network cable is laid prescription can access to the Internet, and now mobile Internet technology, the people can use mobile Internet access. Especially with the recent issuance of $4 \mathrm{G}$ licenses and put into use, the telecom operators continue to upgrade network implementation, so that the mobile signal to achieve full coverage of the whole period. Consumers, whether at work or in leisure and entertainment, no matter where they are, only the signal can successfully access shared information. The second is the integration of information and intelligence. Computer since its birth, after years of development, has now developed to the tablet and handheld computers, the volume and quality is getting smaller, and the mobility and function is increasingly strong, but also able to integrate GPS and gravity sensor, etc. In recent years, the emergence of new technologies, in order to show the characteristics of intelligence and integration of enterprise. Third, the new media has gradually become the dominant media. Traditional media because the publicity on a one-way, information has limited carrying capacity, its high cost and other characteristics, are gradually being made new media that is the Internet. Information carrying capacity of the new media is huge, low cost communication, and information between the recipient and have the interaction and so on, so has gradually become the dominant media.

\section{The main impact of informatization on China's tourism industry chain}

The first is to better enhance the contact of the tourism industry chain. Tourism industry chain and other industrial chain is different in that it has a lateral chain belonging to contact each other closely 
enough, easily their own array. Through tourism industry chain, travel companies can provide services for tourists alone autonomous, while the traditional sense of internal tourism industry chain link closely enough, resulting in limited tourism resources is difficult to obtain a reasonable allocation that generate tourism resources are wasted and so irrational phenomenon. Meanwhile, the tourist industry, the lack of an integrated inter-chain thinking, in intangibles increased the cost of travel groups of tourists, but also increase the physical and psychological burden for tourists. Tourism industry chain information in an era of mobile Internet can rely actively support technology, more accurate, efficient and easy exchange of all types of information, more rational allocation of various types of tourism resources, to ensure the smooth and unobstructed information, and thus able to achieve our Travel virtual integration, so that visitors to achieve all kinds of tourist demand in the same page. Of course, the tourist industry chain information to communicate between each other can also provide a positive reference for the virtualization process of the tourism industry entities, which can promote China's tourism industry to maintain cluster development.

The second is to speed up the process of extending our tourism industry chain. Currently, the level of information of the tourism industry as a whole is not high enough, all kinds of tourism business information is often taken in the form of semi-facts. Although the vast majority of travel agents have been able to achieve the tourism business computer entry and operation, but not yet able to fully use the computer plus Internet plus mobile phones of this model to improve existing tourist business. Expand its business even staying in the dependent increase tourism operators and the number of franchisee outlets to achieve, and the business development will greatly enhance the social cost of travel and the number of franchisee outlets increased somewhat after, difficult to manage tourism enterprises will enhance the synchronization, leading to the conduct of tourism business cannot achieve unity, even a negative impact on the brand of the travel agency. In the case of the continuous development of information technology, the traditional tourism business is bound to reduce its revenue will decline, tourism companies still need to actively adapt to the demands of the information age, accelerate update and improve the traditional approach to business, continue to extend its tourism industry chain.

The third is to accelerate the innovation of the tourism industry of the marketing chain. In the past, tourism marketing is usually implemented using traditional media, that is, in the press, television, radio and other media advertising, issuing leaflets, door to door service and other ways to implement marketing. Tourism marketing in the traditional sense in the current information age fast upgrading has produced shaken, mainly in the audience crowd is a single, cost of the product is extremely expensive, the amount of information carried by a very small, the effect of publicity is not enough significant, unable to keep pace with current developments of the times. In view of this, marketing must effectively be transformed, to adopt a new media marketing methods to attract the majority of tourist visitors. The so-called new media, tourism marketing, refers to the application of micro letter, microblogging, e-mail and online advertising and other new media to promote its tourism industry. For example, I entered the Sina microblogging official website among the "tourist attractions" that keyword to search, and immediately be able to get 1000+ search results, resulting, microblogging tourism marketing this new model has been great promotion and attention, while others, such as micro-channel, online advertising, etc. but also has been rapid development, just open the portal, could be seen at any time relevant to tourism advertising.

\section{The countermeasures to strengthen the tourism industry chain establishment under informatization age}

\section{Use long-term vision to implement tourism industry planning}

Under the information age, China's tourism industry planning and design capability has been greatly improved, but at the same vision of the planning requirements are becoming more and more urgent. Although current data mining technology with commercial operation mode can be quickly transformed into a wealth of tourism products, but the data needs of the tourism industry planning is 
often at a decentralized stage, it has not yet formed a large scale, a systematic planning tools. Early in 1953, the Beijing authorities in the brewing archway was demolished, the Ministry of Culture to discuss when to convene the relevant personalities, ancient architecture expert once said Lin Huiyin, antique demolished, then, we will regret in the future, even if then it is to be restored, after all, fake antiques. Half a century after the 2004 September, Lin Huiyin mouth said "fake antique" Yongding completed in Beijing, which just validated the planning and design of the tourism industry must have a vision. The so-called technological progress, it should make it easier planning tools, therefore, long-term planning of thinking and ideas will seem even more valuable. So, which requires engaged in tourism planning principals have long-term vision should be more than ever, from the role thoroughly transformed into the role of property developer companies.

\section{Depth exploration for the tourism online experience}

Tourism consumption is a very typical experiential consumption. The process includes the travel experience of major expectations before the journey into the experience and feelings, evaluation conducted after travel and so on. Travelers will be to publish their own reviews or travel through the network, which is to share travel experiences or feedback. Therefore, the tourism industry should pay more attention to deeper mining tourism experience, should make tourism consumption is not just a consumer of it, but to make reservation and payment is no longer just a reservation and payment only, it is a worth sharing with family, relatives and friends, show off the content, but also can serve as a reference and guide others to travel, it is worth further attention to other travelers and comparisons. According to a survey, in 2014, the National Consumers who use Ctrip, the same way, to where US group, the public comment, donkey mother, a hornet's nest and other tourist sites, published a total of more than 16 million hotel reviews information pieces, covering the whole country more than 40,000 The hotel, with an average every day to generate 40,000 reviews information. One of the above comments also appear in the travel business information of its service an important part, but also happens to be more than Reviewer behavior, so that consumers who experience the process of consumption becomes more vivid and interesting. Today, the majority of consumers for personalized travel requirements becoming increasingly high, like the pursuit of modern people who travel products or travel services and its own individual interests and life goals coincide with each other, in fact, this is the depth of the travel experience the requirements. Tourism industry on this point must have a more comprehensive and in-depth understanding. In addition to the payment of the mobile terminal functions, the more important is to bring the social aspects of the function of consumers, in order to effectively help achieve consumer consumption to quickly issued a travel experience.

\section{Have precise positioning on personalized marketing implementation}

We can say that the information age know for personalized marketing techniques have already had a comprehensive manner. Searching through large data, the consumer's own prime favorite information is often transmitted directly to the top of its mobile terminal, however, the effectiveness of the marketing will have to depend on exactly how to implement personalized marketing is not sufficiently precise. Many consumers are back before travel, tourism chose to use Baidu, a hornet's nest and other sites to collect information on all aspects of the destination, and then use Ctrip, the same way, go where other sites to implement the tickets, booking hotels, scenic spots and other related Order services, travel back after the review of the travel procedure will be carried out through the booking sites, micro-channel circle of friends, QQ space or microblogging, review and share. Modern consumers are differentiated selection reflects the precise extent of the difference is not the same online platform as well as having areas, can well meet the modern needs of personalized travel services. It is because of the use of information technology tools, so consumers will be able to advance to the travel destination weather conditions, traffic conditions, accommodation and catering and tour information fingertips. Of course, in order to achieve a more accurate positioning to implement personalized marketing, it must implement a comprehensive and sustained improvement in technology innovation and management innovation. For example, by positioning location information travelers dig, website operators can provide real-time traveler to the current location of 
many of the relevant service information, vehicle navigation information, road congestion information, visit the most reasonable path selection information, specialty restaurants recommended information, even information to travelers location-based dating and travel in areas such as safety and rescue. These functions are to be designed to promote by means of information for consumers, its price tends to be very low even for free, and however, once difficult to achieve precise positioning, that these are also non-existent, and there are not any results.

\section{Rapid response to provide quality services}

The information age depends on large data mining and processing technology, today's travelers before travel, during and after the remote data support are able to get the perfect present. Specifically, before travel, consumers are going to master scenic, will stay in hotels and local food, and other related information; in travel among consumers can enjoy anytime, anywhere positioning navigation buffet and buffet guided tours, paging services and other related services; After the trip, consumers can also make a personalized review by the client network, and publish and display their written travel and so on. Of course, the travel companies need to increase support for remote data requires time to enhance the capacity of rapid response. This requires a large data systems to support, but should also have the ability to quickly react. On the contrary, once the online access to relevant information and failure to pay is limited, etc., it will reflect line services although is complete, but the reaction is still not fast enough problems, this way, consumers for online consumer satisfaction inevitable will be reduced, therefore, the need to constantly improve the technical support system to provide comprehensive services.

\section{Conclusion}

In summary, under the conditions of information technology, China's tourism industry information communication emerged new situations and changes, the traditional hierarchy of informatization communication forms have been completely broken, all kinds of information reach to consumers rapidly and at very low the cost, which greatly ease the original information asymmetry. Meanwhile, by the use of modern information technology, major travel companies have enough strength to form a modern network marketing mechanisms, and binding with other electronic financial services providers, to provide a comprehensive one-stop service for the majority of tourists, so as to promote the perfection of China's tourism industry chain.

\section{Acknowledgments}

This paper is the project for 2015 Humanities and Social Sciences Research of Education Department in Henan Province, project number: 2015-QN-222; It is also the project for 2015 Association of Social Sciences in Economic Entity Association of Henan Province, project number: SKL-2015-3287.

\section{References}

[1] Zhao Xiaoyun. Research for the special nature of the tourism industry and the basic form of tourism industry chain. Shanghai Economic Research, 2010 (6).

[2] Zhang Gongrang, Wang Weiwei. On Construction and Integration of Tourism Industry Chain. Commercial Times, 2010 (20).

[3] Li Renjie, Lu Zi. The future development of the personalized recommend services: temporal integration Tourism Tribune, 2011 (10).

[4] Zhang Lingyun, Li Nao, Liu Min. The basic concepts and theoretical system of wisdom tourism. Tourism Tribune, 2012 (5). 
[5] Luo Chengkui. Application technologies of Big Data in the wisdom tourism. Tourism Overview (second half), 2013 (8).

[6] Guo Shu. Analysis for the Economic characteristics of the tourism industry chain and market inefficiencies Origin. Liaoning University (Philosophy and Social Sciences), 2014 (3). 